\title{
What Determines the Position and Intensity of the South Atlantic Anticyclone in Austral Winter?-An AGCM Study
}

\author{
IngO RichteR* and CaRlos R. Mechoso \\ Department of Atmospheric and Oceanic Sciences, University of California, Los Angeles, Los Angeles, California \\ ANDREW W. ROBERTSON \\ International Research Institute for Climate and Society, Palisades, New York
}

(Manuscript received 5 December 2006, in final form 24 April 2007)

\begin{abstract}
The South Atlantic anticyclone is a major feature of the austral winter climatology. An atmospheric general circulation model (AGCM) is used to study the dynamics of the South Atlantic anticyclone by means of control simulations and experiments to investigate sensitivity to prescribed orography, sea surface temperatures, and soil wetness. The South Atlantic anticyclone in the first control simulation is unrealistically zonally elongated and centered too far west-errors typical of coupled ocean-atmosphere GCMs. Results of the sensitivity experiments suggest that these deficiencies are associated with another family of systematic model errors: the overprediction of convection over the tropical land surfaces, particularly over eastern tropical Africa and India, and the concurrent large-scale westward shift in the divergence center at upper levels and the convergence center at lower levels. The results also confirm the important role of South American and African orography in localizing the South Atlantic anticyclone over the ocean. Other factors, however, like the regional zonal gradients of sea surface temperatures, are found to have only a minor impact on the anticyclone. To further substantiate these findings, the wintertime anticyclone is examined using a revised version of the atmospheric GCM. Improvements are found in both the anticyclone as well as the Asia-African summer monsoon circulations. The results demonstrate the existence of links between intensity and structure of the wintertime South Atlantic anticyclone and the major summer monsoons in the Northern Hemisphere.
\end{abstract}

\section{Introduction}

\section{a. Background and motivation}

Persistent anticyclones cover the subtropical Pacific and Atlantic Oceans in both hemispheres. The centers of these features are located in the eastern portions of the ocean basins, where large-scale subsidence balances strong low-level divergence. Of the four anticyclone regions, the South Atlantic is probably the least studied and least well observed. Yet the eastern South Atlantic

\footnotetext{
* Current affiliation: International Pacific Research Center, School of Ocean and Earth Science and Technology, University of Hawaii at Manoa, Honolulu, Hawaii.
}

Corresponding author address: Ingo Richter, International Pacific Research Center, SOEST, University of Hawaii at Manoa, Honolulu, HI 96822.

E-mail: irichter@hawaii.edu

DOI: 10.1175/2007JCLI1802.1

(C) 2008 American Meteorological Society is a region where general circulation models (GCMs) of the coupled ocean-atmosphere system typically exhibit serious errors in the form of a severe warm bias in simulated sea surface temperatures (SSTs). This bias in coupled GCM simulations tends to be accompanied by an erroneous westward shift of the South Atlantic anticyclone, consistent with weakened southeast trade winds and the combined effects of reduced evaporative cooling, upwelling, and stratocumulus. Coupled modeling studies (Ma et al. 1996; Large and Danabasoglu 2006) suggest that these simulation deficiencies over the eastern tropical South Atlantic can affect the whole ocean basin with potentially serious consequences for the simulated tropical Atlantic variability (TAV). Indeed, only one coupled GCM in the intercomparison study by Davey et al. (2002) produced an SST gradient of the right sign along the equatorial Atlantic. The other models obtained a reversed zonal gradient due to a warm bias of up to $4 \mathrm{~K}$ near the African coast. More 
(a) ERA 40

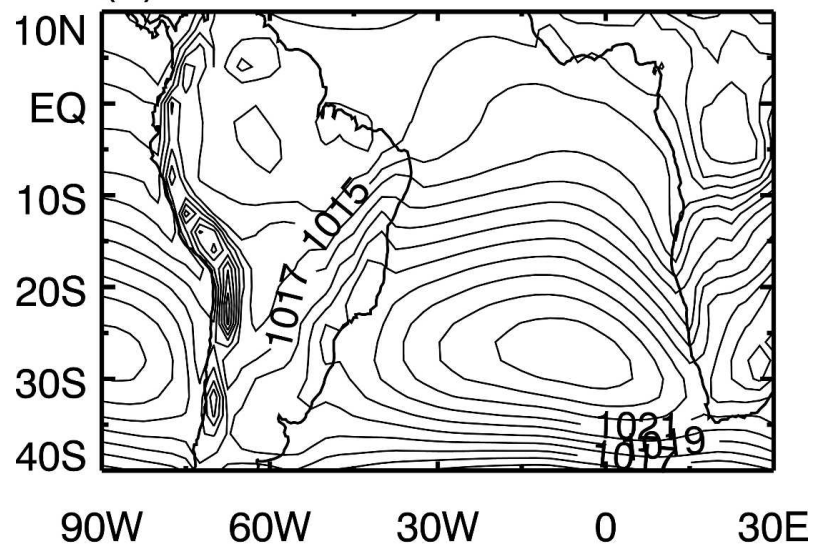

(b)

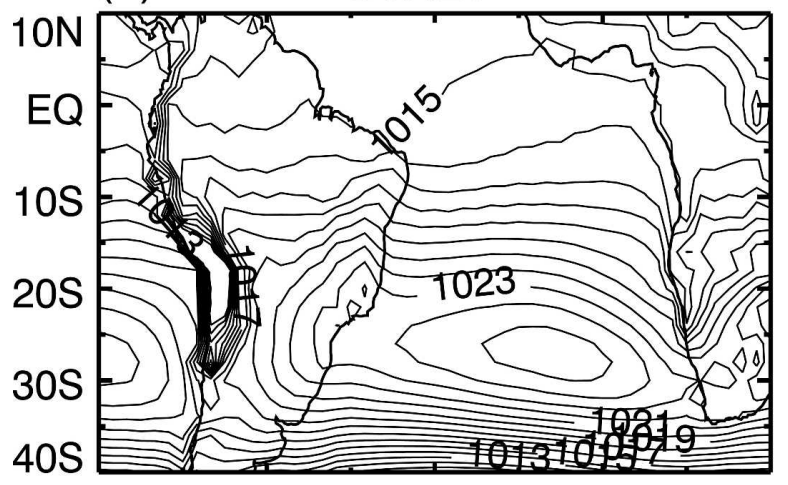

90W 60W 30W $0 \quad 30 \mathrm{E}$

FIG. 1. SLP in July (long-term mean) for (a) ERA-40 and (b) CTRL1 (contour interval is $1 \mathrm{hPa}$ ). The anticyclone in CTRL1 is rather elongated in the zonal direction and not as well confined over the ocean as its counterpart in the reanalysis data.

recent intercomparison studies by Breugem et al. (2006) and Stockdale et al. (2006) show that tropical Atlantic biases remain a serious problem in coupled ocean-atmosphere models. At the present time, most coupled GCM predictions of tropical Atlantic SST are matched or outperformed in skill by statistical models or persistence forecasts (Repelli and Nobre 2004).

While the warm bias over the southeastern Atlantic is likely to contribute to the poor simulation of the anticyclone in coupled GCMs (Seager et al. 2003), uncoupled atmospheric GCMs (AGCM) with SSTs prescribed from an observed climatology can also exhibit serious deficiencies in their simulation of the South Atlantic subtropical high, as illustrated in Fig. 1. These deficiencies can be particularly acute and potentially damaging during austral winter, when the seasonal equatorial cold tongue and trade winds over the southeastern Atlantic are strongest. The observed Atlantic zonal SST gradient at the equator peaks around JulyAugust, which is the time when the coupled GCM errors are large, and the influence of the southern subtropical high on the equatorial region is strongest. An analysis of the errors in the atmospheric component alone, therefore, is a prerequisite for the better understanding of the performance of coupled simulations.

The above considerations suggest that the South Atlantic anticyclone plays a vital role in the Atlantic's mean climatology. Variations in the strength of the anticyclone have also been linked to interannual and decadal modes of Atlantic SST variability in the South Atlantic (Venegas et al. 1997; Servain et al. 1999; Wainer and Venegas 2002) as well as the tropical Atlantic (Robertson et al. 2000; Barreiro et al. 2002; Huang and Shukla 2005; Huang et al. 2005; Trzaska et al. 2007). The comparative narrowness of the Atlantic basin compared to the Pacific suggests that terrestrial processes over the adjacent continents may play a larger role in TAV than in the El Niño-Southern Oscillation (ENSO) and be particularly relevant to the climatology of the South Atlantic anticyclone.

The present paper studies the dynamics of the South Atlantic anticyclone in the context of an AGCM that exhibits the principal deficiency seen in coupled models - namely a westward displacement of the anticyclone. A set of sensitivity experiments are carried out, based on the findings of previous studies discussed below, to test the model's sensitivity to orography on the African and South American continents, prescribed SSTs in the South Atlantic, land surface conditions in Africa, and parameter changes in the model's gravity wave drag parameterization. Our findings point to the decisive influence of the summer monsoonal circulations of the Northern Hemisphere over Africa and Asia. A revised version of the model is also examined in which the monsoonal circulations are significantly improved, with important implications for the South Atlantic anticyclone. Consistently with the improvement, the sensitivities found with the previous version are weaker than those of the revised version. Though initially motivated by coupled model results, our approach based on an uncoupled AGCM is shown to yield new insights into the processes affecting the subtropical anticyclone over the South Atlantic.

\section{b. Previous studies}

Previous studies have identified several mechanisms that control the strength and position of the South Atlantic anticyclone, with contrasting mechanisms dominating in summer and winter; the summer season has received more attention. Rodwell and Hoskins (2001, 
hereafter $\mathrm{RH}$ ) have addressed the maintenance of the subtropical anticyclones with a comparatively simple atmospheric model forced with heating fields obtained from reanalysis data. In the summer hemisphere, $\mathrm{RH}$ relate the subtropical oceanic highs to the monsoonal circulations over the adjacent continents. The equatorward portion of each anticyclone is interpreted as the Kelvin wave response to the monsoon heating over the continent to the west (here South America), with a poleward-flowing low-level jet (here east of the Andes) required for Sverdrup vorticity balance. A Rossby wave response to the monsoon heating over the continent to the east (here Africa) interacting with the midlatitude westerlies produces adiabatic descent to the west of it, and Sverdrup balance demands the existence of an equatorward jet beneath this descent region, closing off the subtropical anticyclone on its eastern flank. During winter, when convective activity over the continents is weaker, $\mathrm{RH}$ argue that the interaction of orography with the trade easterlies and midlatitude westerlies associated with the "Hadley cell" becomes dominant. The basic impact of the mountains is to block both the trade easterlies impinging on their eastern slope and the midlatitude westerlies impinging on their western slope, and thus induce poleward and equatorward flow, respectively. According to $\mathrm{RH}$, this orographic impact is enhanced through the constraints placed on the flow by the conservation of potential vorticity.

The arguments of RH are particularly pertinent to South America, where summertime convection over land is strong and orography is high, but they are less applicable to southern Africa where topography is lower and its blocking effect on the zonal flow is weaker. During austral winter observational data suggest the existence of an anticyclonic circulation pattern in the lower troposphere centered over the continent (Richter and Mechoso 2004).

Seager et al. (2003) also stress the importance of monsoonal heating in strengthening the summertime anticyclones over the ocean in accordance with $\mathrm{RH}$. Additionally, they find an important contribution from air-sea interaction. Their basic argument is that subsidence drying in the eastern subtropical oceans enhances surface latent heat flux, which helps to maintain cool SSTs there. In the western subtropical oceans, on the other hand, convection is accompanied by poleward flow of warm moist air (according to Sverdrup balance). As a consequence, the subtropical zonal gradient of SST is strengthened and the initial anticyclonic circulation pattern reinforced. Seager et al. (2003) also interpret the existence of the winter anticyclones as subsidence associated with the subsiding branch of the Hadley circulation. This forms a high pressure belt that is then split into individual cells by the large-scale orography. However, the austral winter Hadley Cell is far from uniform, and zonal asymmetries in the heating associated with the intertropical convergence zone and the boreal summer monsoons may have important impacts on the wintertime South Atlantic anticyclone.

The subtropical anticyclones can also be considered in the context of extratropical stationary waves, particularly in the wintertime Northern Hemisphere where these waves result from large east-west thermal contrasts and orography. Linear models have long been used to investigate the relative contributions of orographic and diabatic forcing (Charney and Eliassen 1949; Smagorinsky 1953; Nigam et al. 1986, 1988; Wang and Ting 1999). The linear effect of orography is found to be outweighed by that of diabatic heating and nonlinearities in the wintertime Northern Hemisphere, while extratropical heat sources are found to dominate over tropical ones (Wang and Ting 1999). However, linear models perform less well in the Southern Hemisphere, where the waves are relatively weak throughout the year (Valdes and Hoskins 1989; Wang and Ting 1999).

\section{c. Outline}

The goal of the present study is to examine the dynamics of the South Atlantic subtropical anticyclone during austral winter. Our approach is based on using an uncoupled atmospheric GCM. A set of sensitivity experiments to changes in the model's boundary conditions is designed in light of the studies discussed above; these are described in section 2, along with a brief description of the GCM. The model's simulation of the South Atlantic anticyclone in the first control run (CTRL1) is examined in section 3, which is followed by analyses of the set of sensitivity experiments in section 4 . In section 5 we present a second control run (CTRL2) with a much-improved simulation of the South Atlantic anticyclone, together with some further sensitivity experiments with respect to this new climatology. A summary and discussion of the results is presented in section 6 , with the main conclusions in section 7 .

\section{Experiment design and model description}

This study uses the University of California, Los Angeles (UCLA), AGCM with a horizontal resolution of $2^{\circ}$ latitude $\times 2.5^{\circ}$ longitude and 29 vertical layers with the bottommost layer representing the planetary boundary layer. The parameterization of the boundary layer is based on the mixed-layer approach presented in 
Suarez et al. (1983) with modifications by $\mathrm{Li}$ et al. $(1999,2002)$. The convection scheme is a version of the Arakawa-Schubert parameterization (Arakawa and Schubert 1974), in which the cloud work function quasi equilibrium is relaxed by predicting the cloud-scale kinetic energy (Pan and Randall 1998), which includes the effects of convective downdrafts (Cheng and Arakawa 1997). Shortwave and longwave radiation are parameterized according to Harshvardhan et al. (1987, 1989; more details can be found online at http://www. atmos.ucla.edu/ $\sim$ mechoso/esm/agcm.html). Our reference is a 20-yr simulation (CTRL1 hereafter) with boundary conditions corresponding to an observed SST climatology (Reynolds and Smith 1995).

Two experiments are performed to examine the effects of the South American and African orography, in which the orography is removed from each continent in turn. ${ }^{1}$ Two additional experiments are then made with enhanced orography over each continent in turn. All four simulations are $10 \mathrm{yr}$ in length.

Seager et al. (2003) highlight the role of the subtropical zonal SST gradient in strengthening the anticyclonic circulation over the ocean (see section 1). We test the importance of their results for the wintertime South Atlantic in an experiment with an enhanced SST gradient in the subtropical part of the basin.

The protruding West African landmass and associated circulation patterns such as the West African monsoon can also influence the South Atlantic climate (Philander et al. 1996; Xie and Carton 2004). To obtain a first-order assessment of this impact we set the land surface properties over Africa in the AGCM to desert conditions. This involves setting the surface albedo, vegetation type (which influences surface roughness and exchange coefficients), and soil moisture to values representative of the Sahara region.

Finally, we address the impact of changes in the model's gravity wave drag parameterization. This model feature affects the mass distribution of the simulated atmosphere and thus the sea level pressure (SLP) distribution. The UCLA AGCM uses the gravity wave drag parameterization devised by Kim and Arakawa (1995), which allows for the adjustment of gravity wave drag at the critical height level. We test the sensitivity of the South Atlantic anticyclone to changes in this parameter. The sensitivity experiments to SST, soil wetness, and gravity wave drag are each $5 \mathrm{yr}$ in length. In those experiments a shorter period is sufficient to assess the model's response because the changes in the bound-

\footnotetext{
${ }^{1}$ These were originally performed as part of a study on subtropical stratocumulus (Richter and Mechoso 2004, 2006).
}

ary conditions are not as invasive as the removal of orography.

After the first set of sensitivity tests we turn to an AGCM version that produces a more realistic simulation of the austral winter climatology (Konor et al. 2004). This version has a new formulation of the PBL, in which the vertically integrated PBL turbulence kinetic energy (TKE; see Konor and Arakawa 2001) is treated as a prognostic variable. The predicted TKE is then used to parameterize the surface fluxes of momentum and sensible and latent heat as well as entrainment at the PBL top. This version of the model is used to generate a $20-\mathrm{yr}$ control simulation, referred to as CTRL2. The simulation uses the same vertical and horizontal resolution as CTRL1. Apart from the prognostic TKE, CTRL2 also features several other differences compared to CTRL1. The most important concerns the treatment of cloud liquid water and ice. These are predicted in CTRL1 (Köhler 1999) but diagnosed in CTRL2. Furthermore there are changes in the gravity wave drag parameter and in the ventilation coefficient used in the calculation of surface fluxes.

CTRL2 serves as a reference for further sensitivity experiments that investigate the influence of South Atlantic SST distribution and gravity wave drag on the anticyclone.

Model performance is assessed against a 40-yr climatology constructed from the European Centre for Medium-Range Weather Forecasts (ECMWF) ReAnalysis (ERA-40). Qualitatively similar results were obtained using the National Centers for Environmental Prediction-National Center for Atmospheric Research (NCEP-NCAR) reanalysis (Kalnay et al. 1996).

\section{The South Atlantic anticyclone in CTRL1}

Figure 1 contrasts sea level pressure in CTRL1 and ERA-40 for July. The simulated anticyclone is more zonally elongated than in the reanalysis, with a weak zonal pressure gradient over the ocean between $20^{\circ}$ and $30^{\circ} \mathrm{S}$; it is also centered farther west than in ERA-40 and penetrates into the adjacent continents, particularly to the west. Particularly, the weak zonal pressure gradient is a feature commonly found among uncoupled AGCMs like, for example, the Community Atmosphere Model version 3 (CAM3; results can be viewed at http://www.ccsm.ucar.edu/models/atm-cam/), the Max Planck Institute for Meteorology ECHAM 5 model [data available through the Atmospheric Model Intercomparison Project (AMIP) Web site at http://www. pcmdi.llnl.gov/projects/amip/index.php], as well as other AMIP models. 
(a)

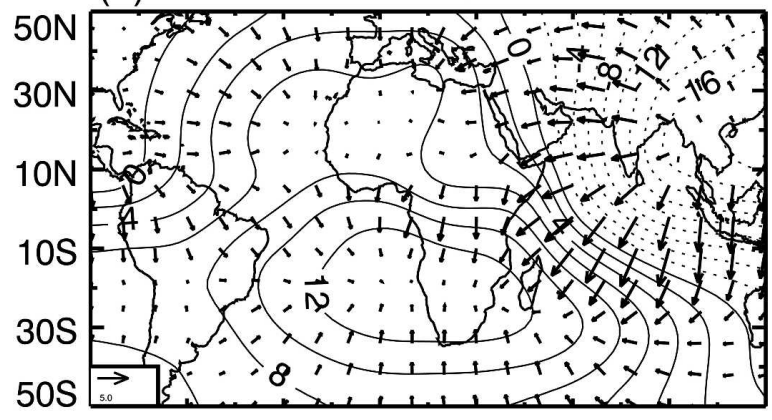

90W 60W 30W 0 30E 60E 90E 120E

(b)

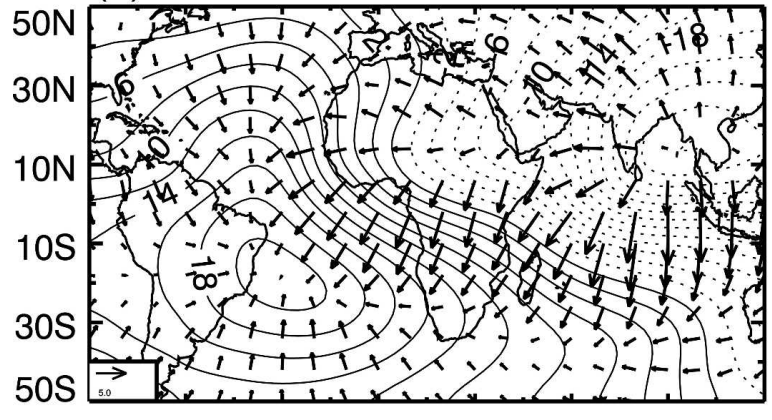

90W 60W 30W 0 30E 60E 90E 120E

FIG. 2. Upper-level (200 hPa) divergent wind (vectors) and velocity potential (contours, $\mathrm{m}^{2} \mathrm{~s}^{-1} \times 10^{-6}$ ) in July for (a) ERA-40 and (b) CTRL1. Negative contours are dotted. The reference vector in the lower left corner of each panel shows $5 \mathrm{~m} \mathrm{~s}^{-1}$. The upper-level divergence associated with the Asian summer monsoon extends much farther to the west in CTRL1 than in ERA-40. Consequently, divergence over the South Atlantic is shifted to the west in CTRL1.

Maps of the divergent wind and velocity potential at $200 \mathrm{hPa}$ in July are presented in Fig. 2. These maps reveal a striking westward shift of the region of upperlevel convergence in the simulation toward the eastern coast of South America. This is accompanied by a westward extension of the upper-level divergence associated with the Asian monsoon, so that the region of strong velocity potential gradients and divergent wind extends all the way to western Africa in CTRL1, while it is largely confined to the western Indian Ocean in ERA-40. These features imply a planetary-scale displacement of the model's divergent circulation associated with the Northern Hemisphere summer monsoon systems over Asia and Africa. We have verified that the upper-level velocity potential pattern in the ERA-40 data is closely matched by its counterpart in the NCEPNCAR reanalysis.

The model's tendency to shift the South Atlantic subtropical anticyclone to the west is consistent with the vertical velocity fields at $500 \mathrm{hPa}$ shown in Fig. 3: the

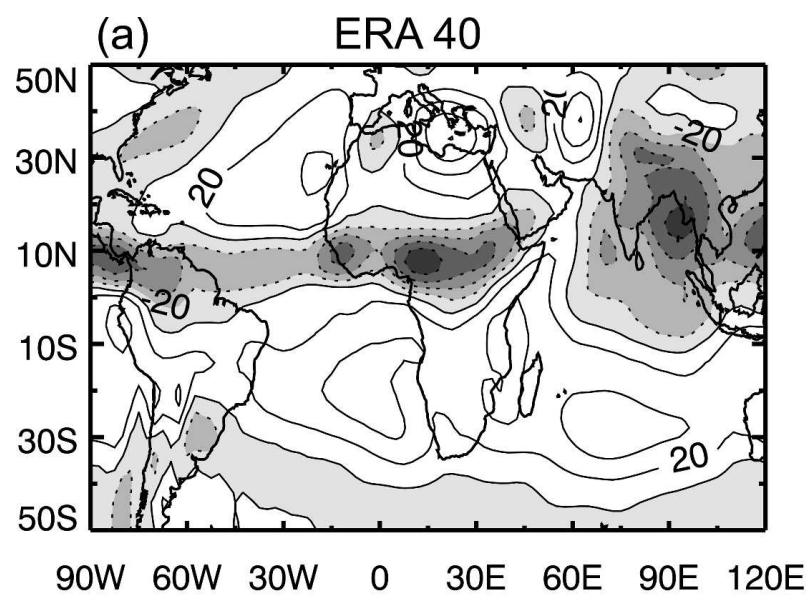

(b) CTRL1

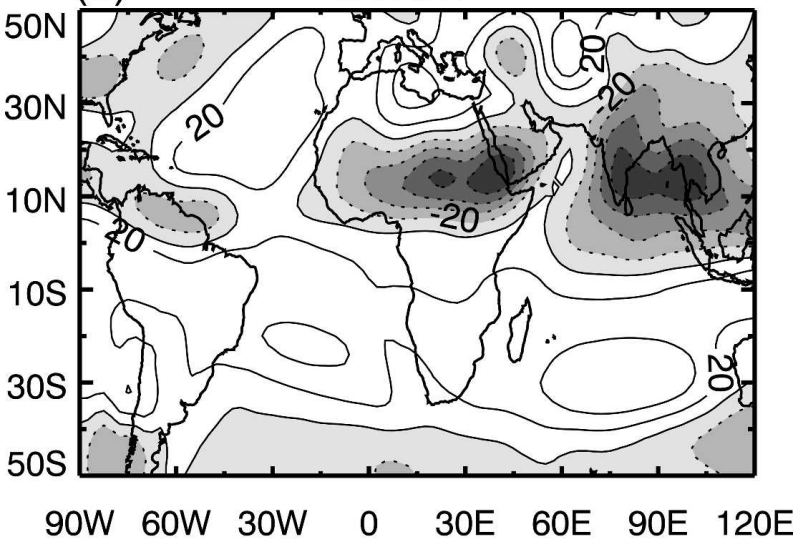

FIG. 3. Vertical $p$-velocity [hPa day ${ }^{-1}$ ] at $500 \mathrm{hPa}$ in July for (a) ERA-40 and (b) CTRL1. Negative values are shaded. This figure shows the lack of separation between African and Asian convection and a westward shift in subsidence over the South Atlantic. While ERA-40 places the maximum subsidence at around $0^{\circ}$, CTRL1 shifts it to $20^{\circ} \mathrm{W}$.

region of maximum descent in CTRL1 is located in the western subtropical South Atlantic, as opposed to the eastern part of the basin in ERA-40. Tropical convection in CTRL1 is concentrated over eastern equatorial Africa with a local maximum east of the Ethiopian highlands, while in ERA-40 it is strongest over western Africa, with two local maxima over the coast of Guinea and over Nigeria. The upward vertical motion in CTRL1 is therefore located farther east and poleward than in ERA-40, so that the regions of convection associated with the Asian and African monsoons tend to merge in the simulation.

The regions of precipitation in CTRL1 and ERA-40 (Fig. 4) generally coincide with those of upward vertical velocity, with the exception of the Ethiopian highlands at $40^{\circ} \mathrm{E}$, where upward motion is of comparable mag- 
(a)

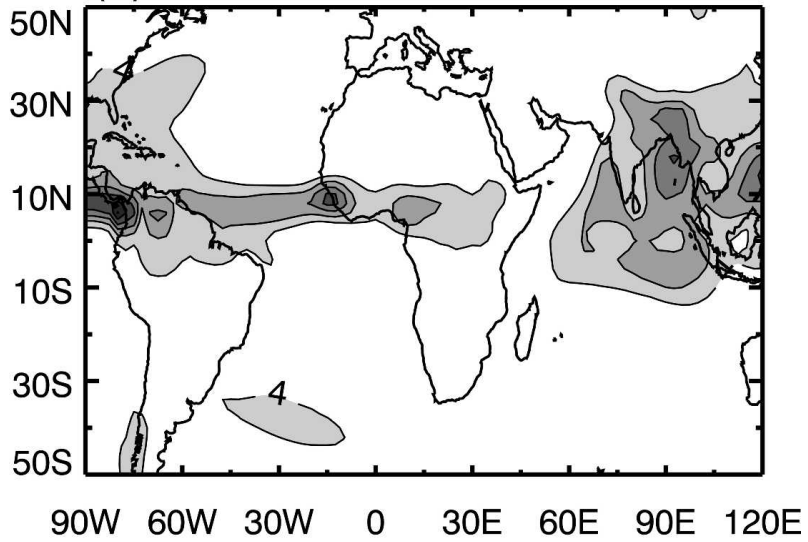

(b)

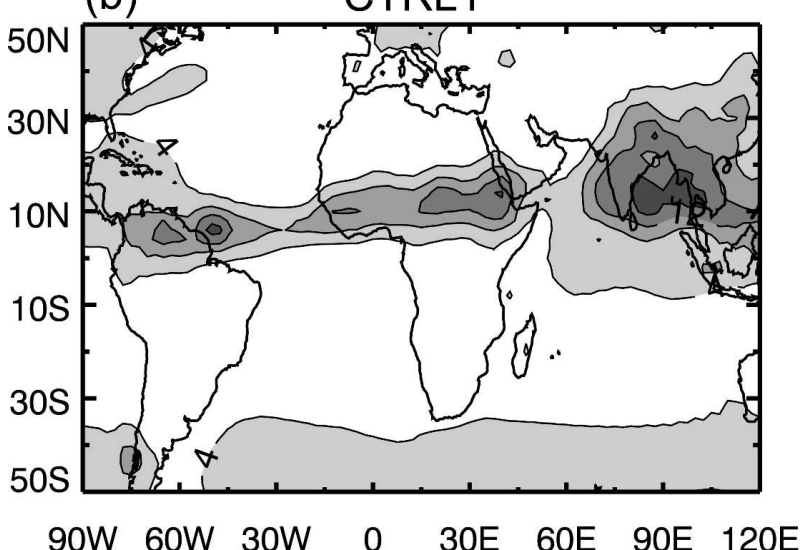

(c)
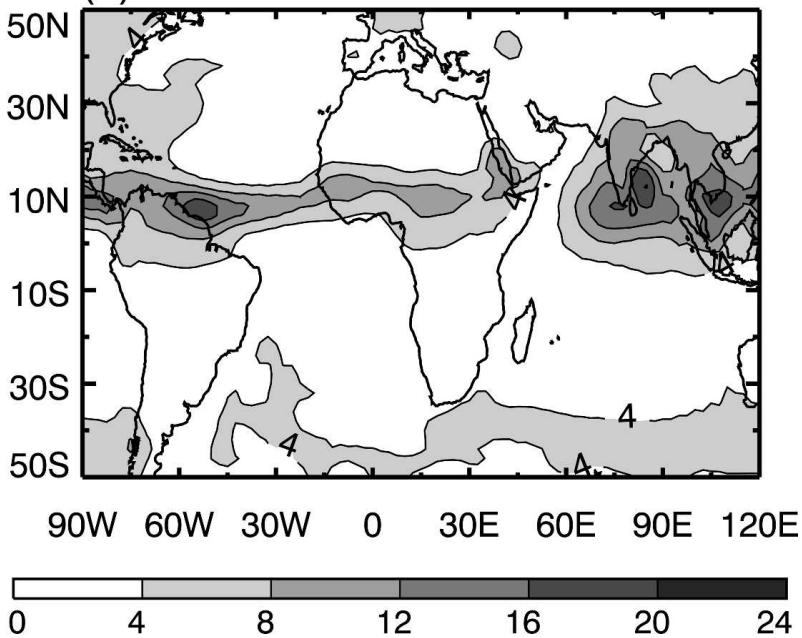

FIG. 4. Precipitation $\left(\mathrm{mm} \mathrm{day}^{-1}\right)$ in July for (a) ERA-40, (b) CTRL1, and (c) CTRL2. The separation between African and Asian monsoon precipitation is much clearer in ERA-40 than in CTRL1. (a)

ERA 40

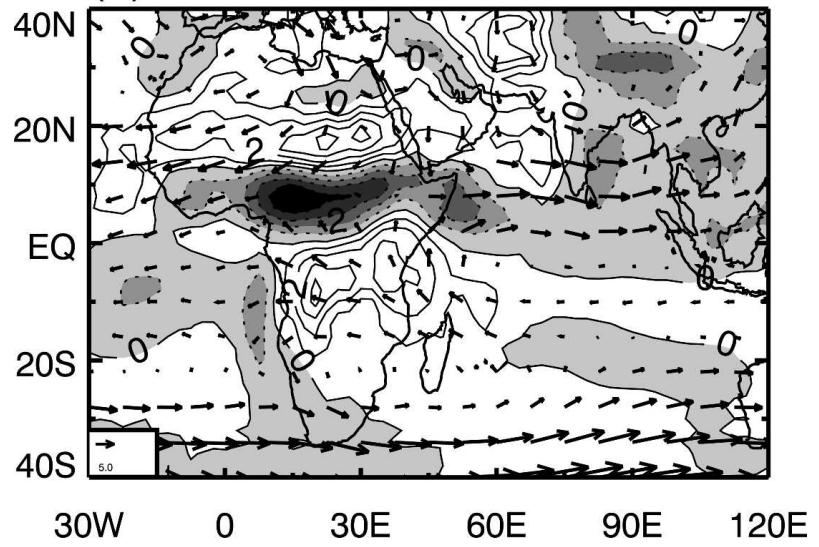

(b)

CTRL1

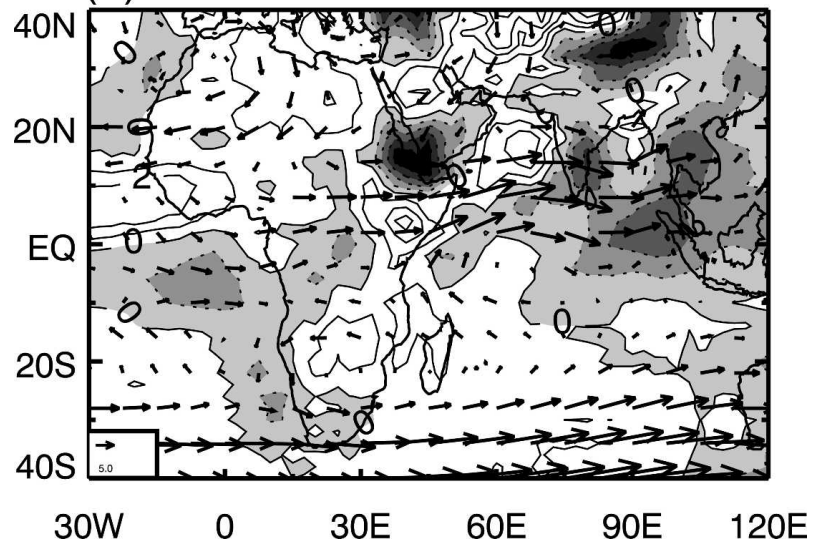

FIG. 5. Divergence $\left(1 \mathrm{~s}^{-1} \times 10^{-6}\right)$ and horizontal wind at 700 hPa in July for (a) ERA-40 and (b) CTRL1. The reference vector in the lower left-hand corner shows $5 \mathrm{~m} \mathrm{~s}^{-1}$. Negative values are shaded.

nitude in both CTRL1 and ERA-40 but precipitation is much more intense in the simulation. The intense upward motion over the Ethiopian highlands in the simulation appears to be due, at least in part, to orographic uplift. This is suggested by the existence of spurious westerly low-level winds and low-level divergence over the Ethiopian highlands in the simulation (Fig. 5). To obtain a first-order estimate of the orographic uplift in CTRL1, we estimated based on the AGCM output that an air parcel in the PBL just upwind of the Ethiopian highlandhighlands has a temperature of $23.5^{\circ} \mathrm{C}$ and a relative humidity of $85 \%$, yielding a dewpoint temperature of $20.8^{\circ} \mathrm{C}$. Therefore, water vapor in a parcel crossing the Ethiopian highlands at 2000-m elevation would condense releasing latent heat, thus enhancing the vertical motion.

Another feature obvious in Fig. 4 is CTRL1's underestimation of ITCZ precipitation in the central Atlantic. This is consistent with the absence of upward ver- 
tical motion at the 500-mb level in the region (Fig. 3) and indicates that the existing precipitation most likely stems from shallow convection below the 500-mb level. The dry bias over the central Atlantic is also seen among most of the AMIP models. Some of these models feature a wet bias over eastern Africa similar to CTRL1.

The low-level wind fields in Fig. 5 also exhibit a striking difference between CTRL1 and ERA-40: winds over equatorial Africa are westerly in the simulation but easterly in the reanalysis. Additionally, the equatorial flow in CTRL1 is rather zonal and nondivergent, in contrast to the northeast and southeast trade winds seen in ERA-40 over Africa, which converge at about $8^{\circ} \mathrm{N}$ and imply a moisture flux convergence that balances the precipitation there.

The simulation also exhibits a surface cold bias over most of the African continent in July (Fig. 6a). This bias acts to reduce the land-sea contrast with the prescribed SSTs, consistent with the weaker precipitation in the simulation seen in Fig. 4 along the Atlantic coast of Africa near $10^{\circ} \mathrm{N}$. Despite the model's cold bias, evaporation is unrealistically intense as indicated by the very high values of surface latent heat flux in Fig. 6; these are particularly pronounced over northwestern Africa where the surface cold bias has a local maximum. The problem at the continental surface is likely to be exacerbated by the lack of an interactive representation of surface processes in the model.

The patterns of low-level wind, surface temperature, and latent heat flux suggest the following scenario. In CTRL1, the low-level westerlies over western tropical Africa are moistened by the intense local evaporation, but too cold surface temperatures discourage deep convection. When these moisture-laden westerlies encounter the Ethiopian highlands, the orographic uplift triggers substantial condensation and precipitation. This contrasts with the situation in ERA-40, in which moisture transported by the northeast and southeast trade winds converges over western tropical Africa, where higher ground temperatures and low stability encourage precipitation development.

\section{Sensitivity of the South Atlantic anticyclone in CTRL1 to AGCM boundary conditions}

\section{a. Sensitivity to African and South American orography}

In a first series of experiments we examine how altering the orography over Africa and South America affects the South Atlantic anticyclone. The first two experiments have no mountains in each continent and (a) Skin Temperature Difference

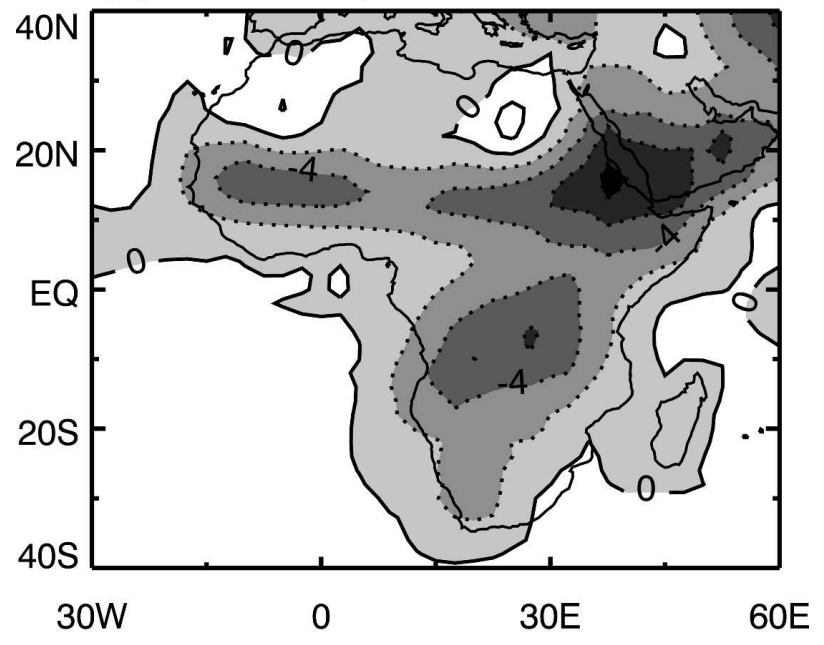

(b) Sfc Latent Heatflux Difference

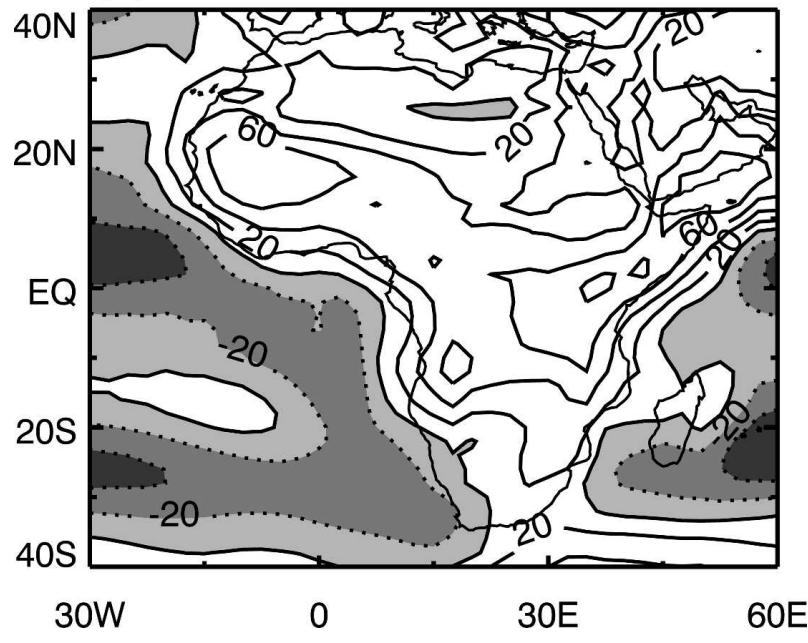

FIG. 6. (a) Ground temperature difference between CTRL1 and ERA-40 in July. CTRL1 features a cold bias over most of Africa. (b) As in (a) but for surface latent heat flux. The contour interval is $20 \mathrm{~W} \mathrm{~m}^{-2}$.

will be referred to as No South American Orography (NSAO) and No African Orography (NAfO), respectively. The third experiment uses orographic heights over South America that have been subjected to less smoothing than those used in CTRL1 (USAO hereafter). The final experiment in the set uses orography in southern Africa that is obtained by raising CTRL1 elevations by an additional $50 \%$. This creates peak heights of approximately $2500 \mathrm{~m}$, which are comparable to values found in high-resolution datasets such as the 5-minute Gridded Earth Topography (ETOPO5) data (National Oceanographic and Atmospheric Administration 1988). This last experiment will be referred to as Enhanced African Orography (EAfO). 
(a) No SAm Orography

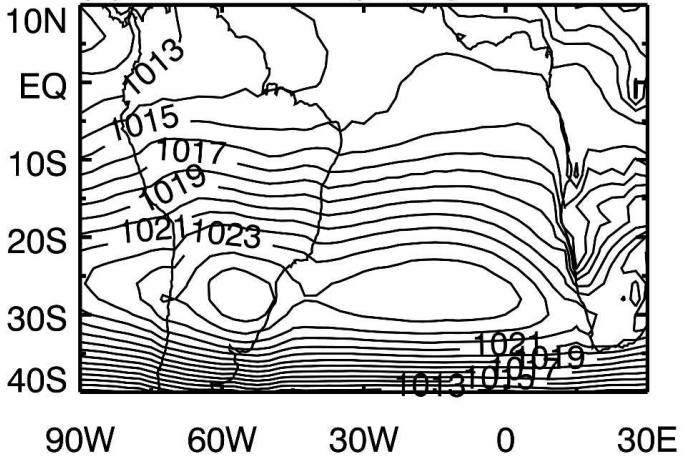

(c) Unsmoothed SAm Oro

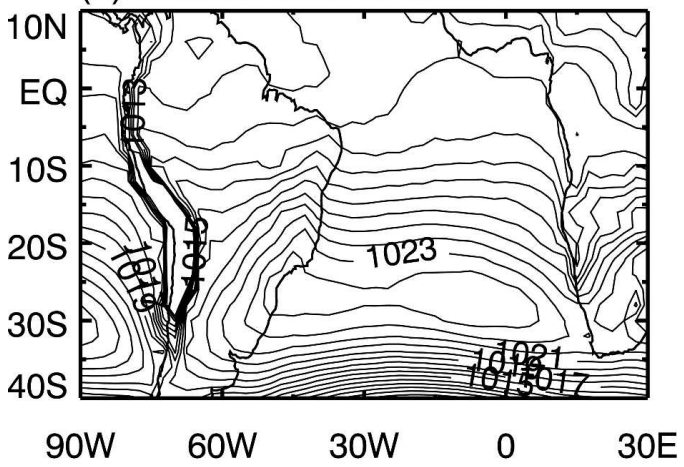

(e) eastern SATL cold SSTA

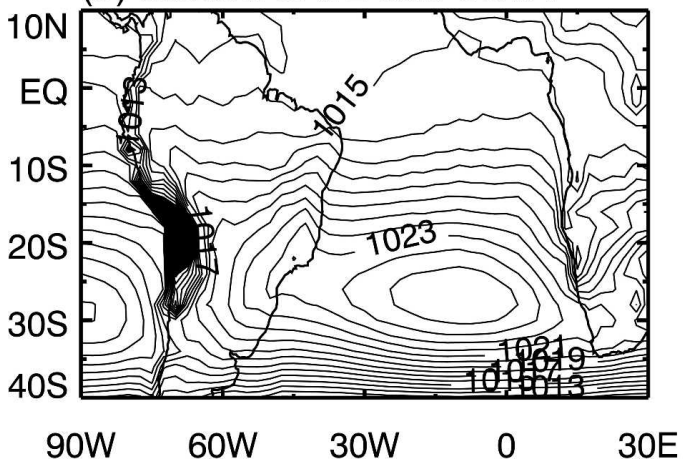

(b) No African Orography

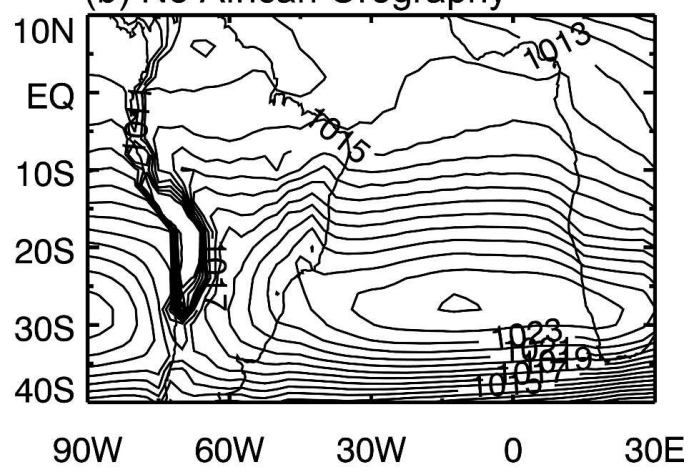

(d) Enhanced African Oro

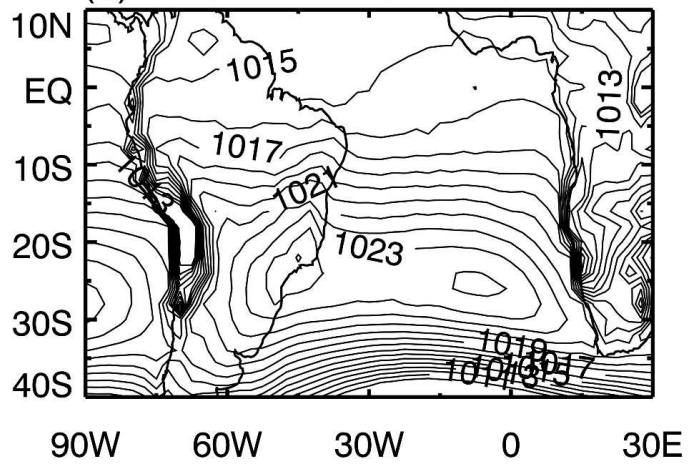

(f) Pan African Desert

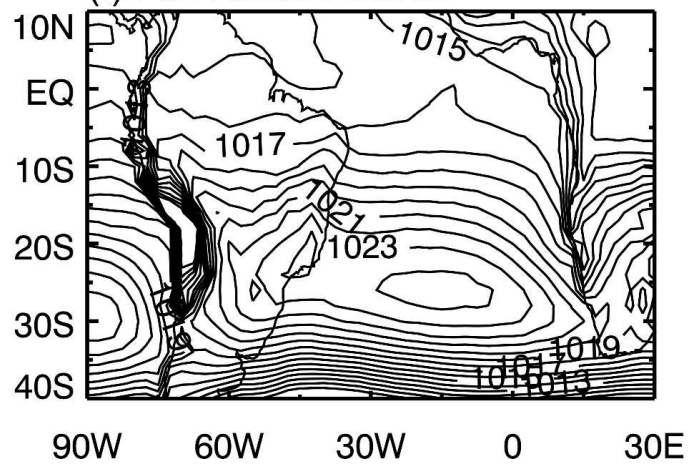

FIG. 7. SLP (hPa) in July for the following experiments: (a) no South American orography, (b) no African orography, (c) unsmoothed South American orography, (d) enhanced African orography, (e) experiment with warm SST anomaly in the western South Atlantic, and (f) African desert.

Figures $7 \mathrm{a}-\mathrm{d}$ shows the July mean sea level pressure in the four experiments. In the experiment without orography over South America (NSAO; Fig. 7a), a local maximum develops over South America as part of a high pressure belt that extends from the west coast of southern Africa to the southeast Pacific. ${ }^{2}$ Similarly, set-

\footnotetext{
${ }^{2}$ The northeasterly winds accompanying this pattern in the South Pacific would presumably also cause a serious reduction in coastal upwelling off the Peruvian coast.
}

ting the orography to zero over Africa (NAfO; Fig. 7b) causes the eastern flank of the anticyclone to extend farther east. The steeper South American orography in USAO, however, does not aid in confining the anticyclonic circulation over the western South Atlantic (Fig. 7c); rather it appears to weaken the zonal pressure gradient over the region and thus adds to the existing problem in CTRL1. The enhanced African orography experiment (EAfO; Fig. 7d) shows a slight improvement along the coast of southern Africa in that the 1021- and 1022-hPa contour lines close off over the 

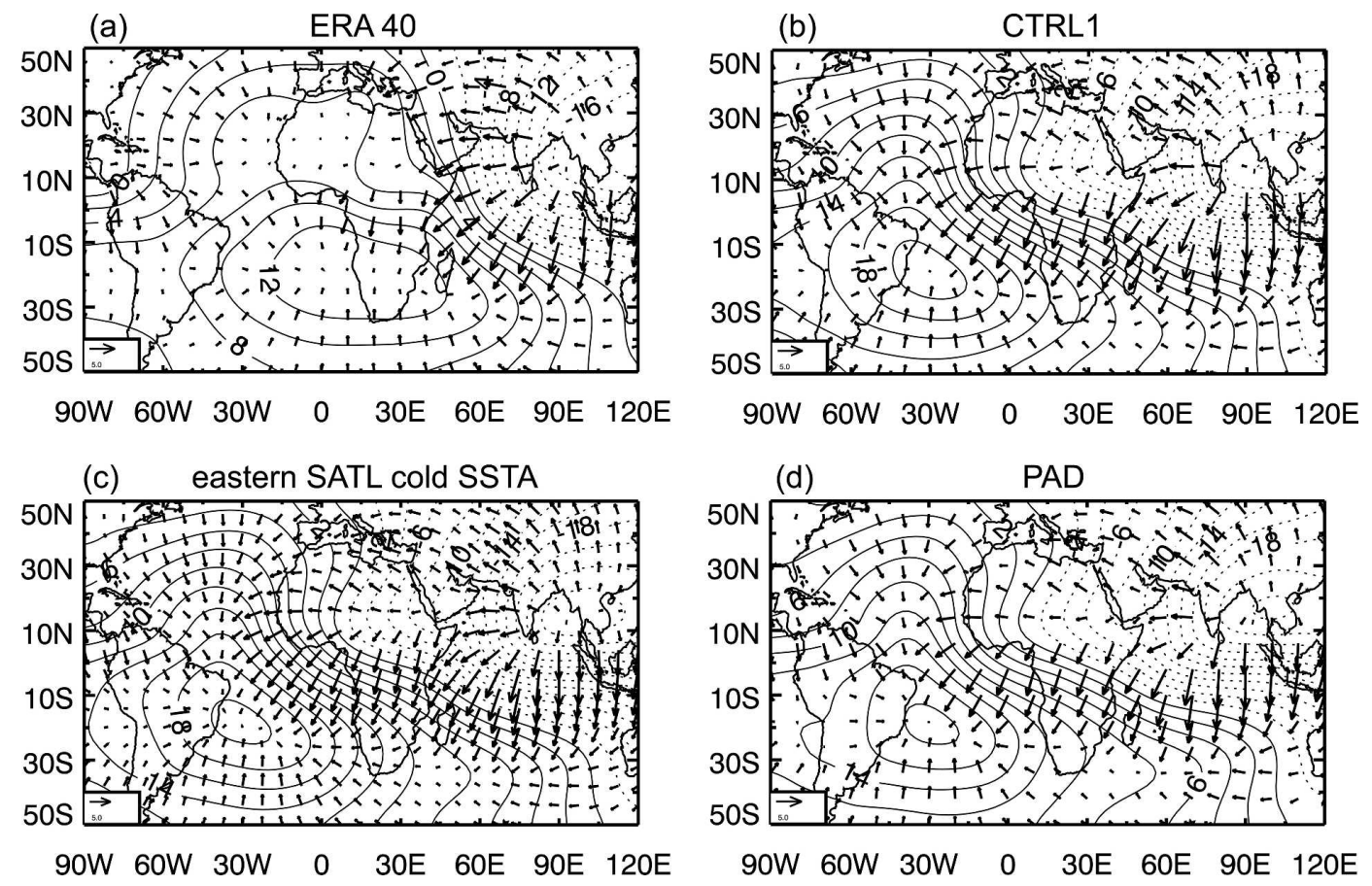

FIG. 8. Velocity potential (contours, $\mathrm{m}^{2} \mathrm{~s}^{-1} \times 10^{-6}$ ) and divergent wind (arrows) at $200 \mathrm{hPa}$ for July in (a) ERA-40, (b) CTRL1, (c) experiment with warm SST anomaly in the western South Atlantic, and (d) Pan African desert experiment.

ocean, which is not the case in CTRL1 (Fig. 1b). In the western South Atlantic, however, the zonal pressure gradient decreases significantly.

In summary, the experiments in this section highlight the importance of orography in breaking up the subtropical high pressure belt into distinct cells during wintertime. However, they also indicate that the smoothed orography used in CTRL1 is already sufficient to achieve this effect, and that using a more detailed orography does not provide any significant improvement to the model's representation of the South Atlantic anticyclone in winter.

\section{b. Sensitivity to Atlantic SST distribution}

Seager et al. (2003) suggest that zonal SST gradients play an important role in strengthening subtropical anticyclones (see section 1).

We test this mechanism in the context of the GCM simulation of the wintertime South Atlantic anticyclone by introducing a cold SST anomaly in the eastern South Atlantic between $30^{\circ}$ and $10^{\circ} \mathrm{S}$. The anomaly is constant in time and has a maximum amplitude of $3 \mathrm{~K}$. The hypothesis of Seager et al. (2003) would predict a strengthening of the anticyclone in the region of the SST anomaly due to increased subsidence.

The cold anomaly is found to cause a moderate strengthening of the anticyclone in July (Fig. 7e), but the circulation in the region does not change significantly (Fig. 8c). The model response appears, thus, to be largely due to local thermodynamic effects. This weak sensitivity might partly be due to the absence of coupled feedbacks in our experiments.

\section{c. Sensitivity to land surface properties over Africa}

In this experiment the land surface properties over Africa are set to desert conditions. The actual values prescribed are 0.01 for effective soil moisture, ${ }^{3} 0.25$ for surface albedo, and a desert vegetation type. This simulation will be referred to as the Pan African Desert (PAD) experiment.

The difference in precipitation between PAD and CTRL1 (Fig. 9) shows greatly reduced rainfall over the Ethiopian highlands in particular and eastern tropical Africa in general. Close to the equator and along the Gulf of Guinea, however, precipitation increases by more than $1 \mathrm{~mm}$ day $^{-1}$. This is accompanied by an increase in moisture flux convergence due to intensified moisture advection from the Gulf of Guinea (not shown).

\footnotetext{
${ }^{3}$ This is not volumetric soil moisture but a relative value that indicates the degree to which the soil is saturated with moisture. Thus, values in the model range from 0.01 to 1 .
} 


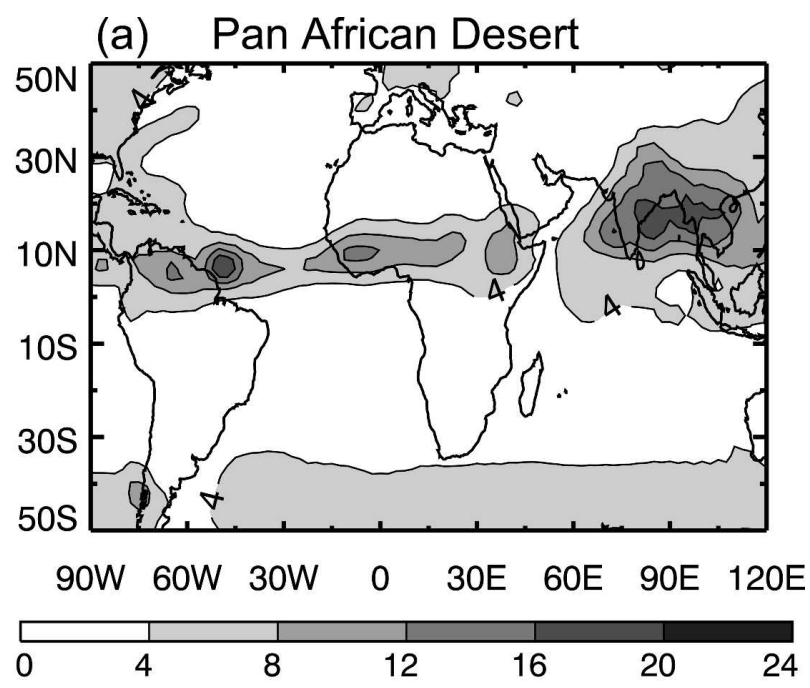

(b)

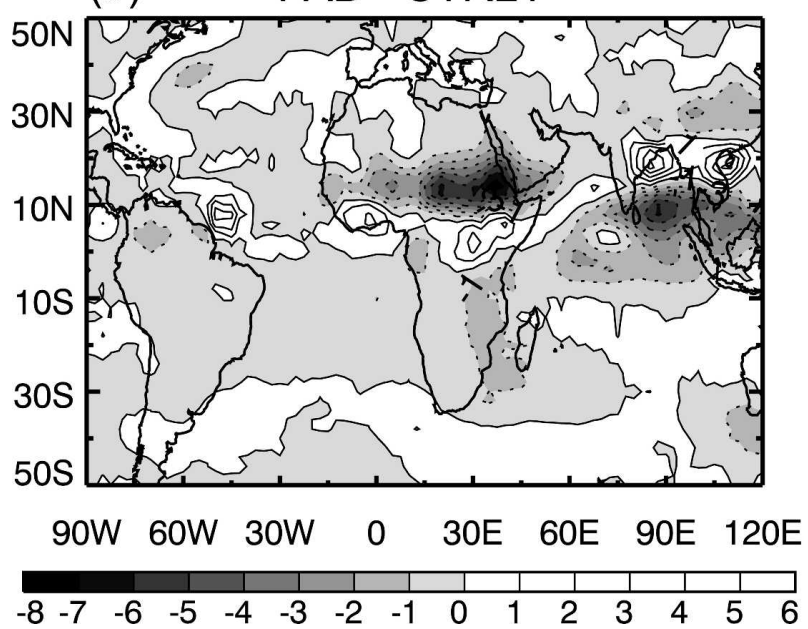

FIG. 9. Precipitation $\left(\mathrm{mm} \mathrm{day}^{-1}\right)$ in July for (a) PAD and (b) the difference PAD - CTRL1. The altered land surface conditions in PAD reduce the excessive maximum over the Ethiopian highlands seen in CTRL1 and also produce a better separation between African and Asian monsoon precipitation.

Despite the general decrease in precipitation over Africa in PAD, the upward vertical velocity actually increases in the midtroposphere over tropical Africa. To gain insight into the reasons for this feature, we compare ground temperatures in PAD and CTRL1 (Fig. 10). PAD shows a warm bias relative to ERA-40 data, with surface temperatures up to $9 \mathrm{~K}$ warmer than in CTRL1, which had a cold bias. The location of the largest temperature difference coincides with the area where the largest difference in prescribed effective soil moisture between the experiments occurs. The difference in latent heat flux (not shown) indicates an inverse pattern with a minimum located where the temperature anomaly is largest. The warmer ground temperatures

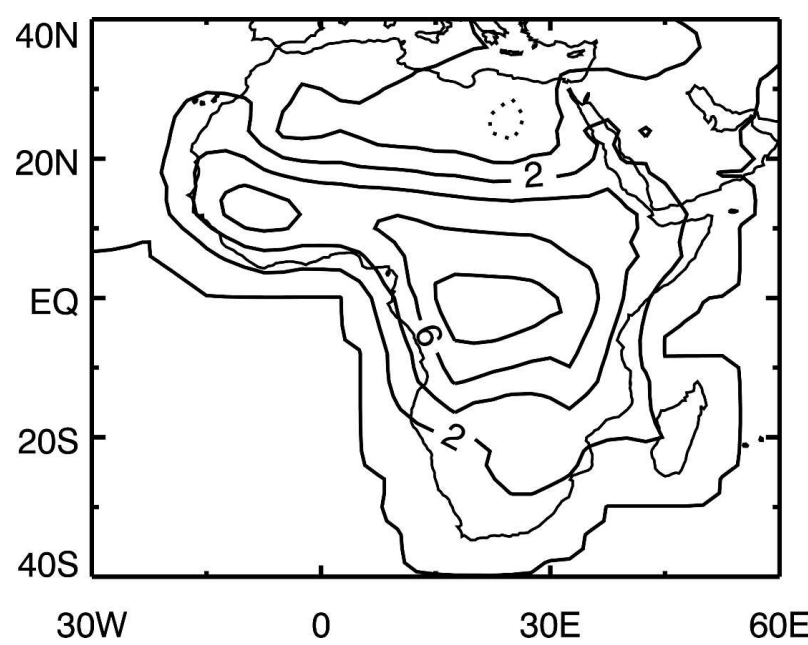

FIG. 10. Skin temperature difference (K) between PAD and CTRL1 for July.

and stronger upward motion are consistent with decreased latent heat flux and dry convection. The lowlevel flow patterns in the two experiments are qualitatively similar with westerly equatorial winds and intense upward motion over the Ethiopian highlands. Precipitation over the latter region, however, is much weaker in PAD. This is associated with the dry land surface and the reduced moisture advection from the west as more precipitation occurs over western tropical Africa.

The sea level pressure field for the PAD experiment is shown in Fig. 7f. The South Atlantic anticyclone is better localized in PAD than in CTRL1, with a stronger zonal pressure gradient over the eastern South Atlantic. To the west, however, there is no significant change in the pressure gradient, so that the anticyclone still extends too far west into South America. These results suggest an important local thermodynamic effect from the increased ground temperatures over southern Africa. This is also supported by the upper-level velocity potential (Fig. 8d), which indicates a weakening of the convergence and divergence centers but no pattern shift.

\section{Sensitivity of the South Atlantic anticyclone in CTRL2 to AGCM boundary conditions}

In this section we examine a second control simulation (CTRL2) made with a recent version of the AGCM that includes a new formulation of the PBL, in which the vertically integrated PBL turbulence kinetic energy is predicted and then used to parameterize the surface fluxes as well as entrainment at the PBL top. One can regard CTRL2 as primarily measuring the sen- 
(a)

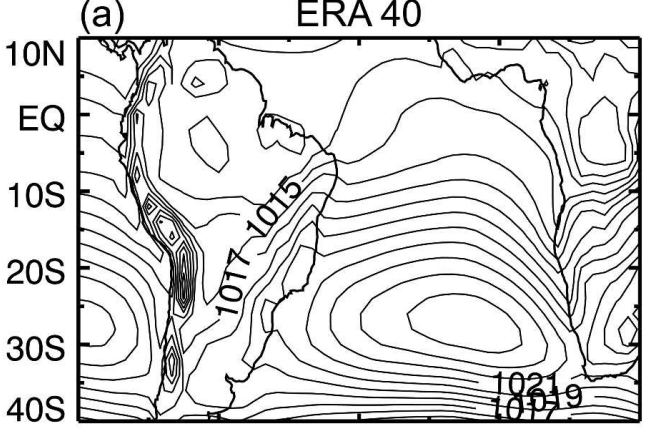

90W 60W 30W 0 30E

(c) CTRL2 - no zonal grad SATL

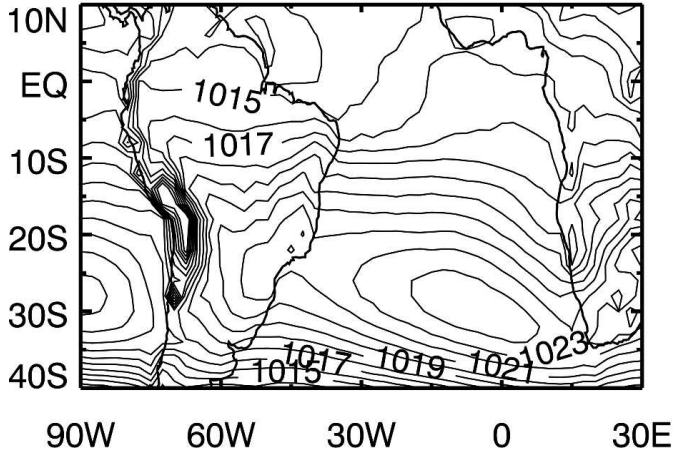

(b)
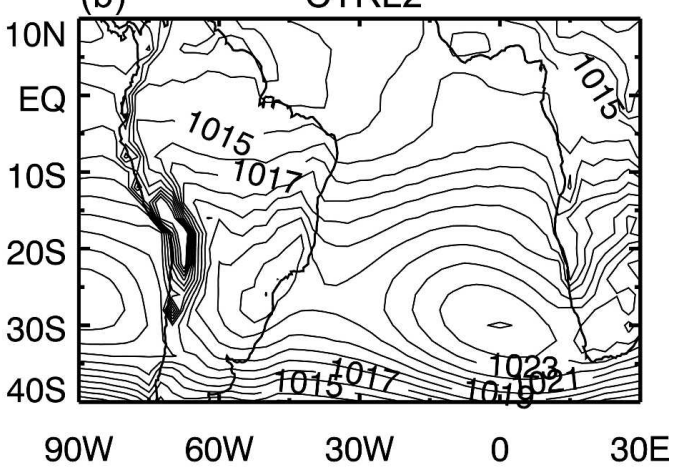

(d) CTRL2 - cleff $=50.0 \mathrm{E} 3$

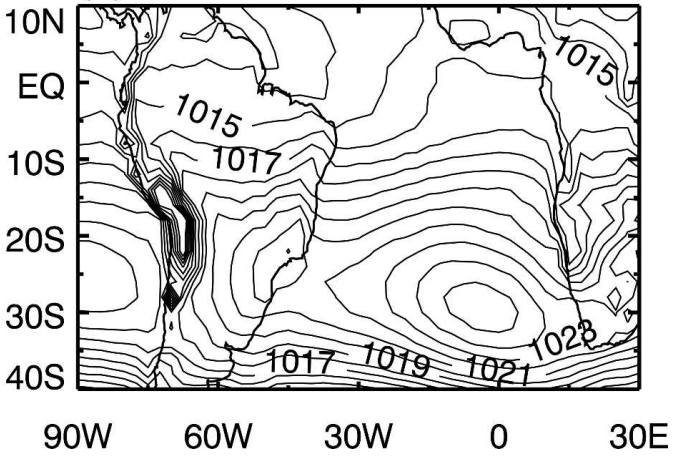

FIG. 11. Difference in vertical $p$-velocity $\left(\mathrm{hPa} \mathrm{day}^{-1}\right)$ between CTRL2 and CTRL1 at $500 \mathrm{hPa}$ in July.

sitivity of a model with a more successful simulation of the austral climatology.

Figure $4 \mathrm{c}$ shows that July precipitation in CTRL2 is generally more similar to ERA-40 than in CTRL1. Consistently, latent heat flux and the amount of moisture entering the PBL from the surface are both found to be reduced in CTRL2, and the troposphere is generally colder and more stable with colder ground temperatures (not shown). In the midtroposphere, the upward vertical motion over equatorial Africa, the Arabian Peninsula, and India is generally weaker in CTRL2 than in CTRL1 (Fig. 11). In the western and central tropical Atlantic as well as the equatorial Indian Ocean, on the other hand, vertical motion is significantly stronger in CTRL2. These differences are reflected in the upper-level velocity potential (Fig. 12), which shows a general eastward shift, resulting in a pattern that is much more similar to ERA-40 than in CTRL1. The centers of convergence and divergence in CTRL2 are more correctly located over the eastern South Atlantic and Southeast Asia. Figure 13 shows that these changes in the divergent circulation are also associated with a much more realistic simulation of the South Atlantic anticyclone, which is more localized in the eastern part of the basin in CTRL2 (Fig. 13b), with a more realistic SLP distribution over the western South Atlantic.

The general eastward shift of patterns in CTRL2 is clearly seen in longitude-height sections of vertical velocity averaged between $30^{\circ}$ and $20^{\circ} \mathrm{S}$ (Fig. 14). CTRL1 places the maximum subsidence at $450 \mathrm{hPa}$ and $20^{\circ} \mathrm{W}$, CTRL2 places it at $500 \mathrm{hPa}$ and $5^{\circ} \mathrm{W}$, and ERA-40 places it at $650 \mathrm{hPa}$ and $5^{\circ} \mathrm{E}$. Thus the center of downward motion over the South Atlantic in CTRL2 is closer to Africa but still falls short of the ERA-40 reference data that place the maximum another $10^{\circ}$ farther east.

We have tested the sensitivity of the anticyclone in CTRL2 to a reduction in the zonal SST gradient. CTRL2 is more suitable for this type of experiment because its anticyclone is rather realistic in terms of position and strength. In CTRL1, on the other hand, the anticyclone is weak to begin with so that any deterioration would be hard to notice. The experiment is described in section 5 a.

Apart from the PBL formulation CTRL2 features several other differences (see section 2), among them the value of the ventilation coefficient used in the calculation of surface fluxes of latent and sensible heat, and the value of the parameter in the gravity wave drag 

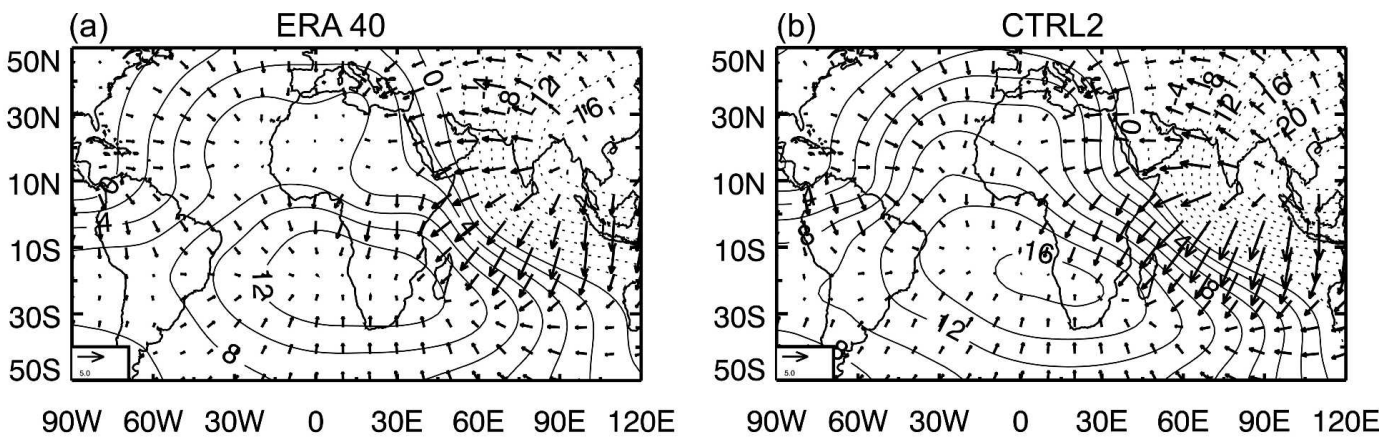

(c) CTRL2 - no zonal grad SATL
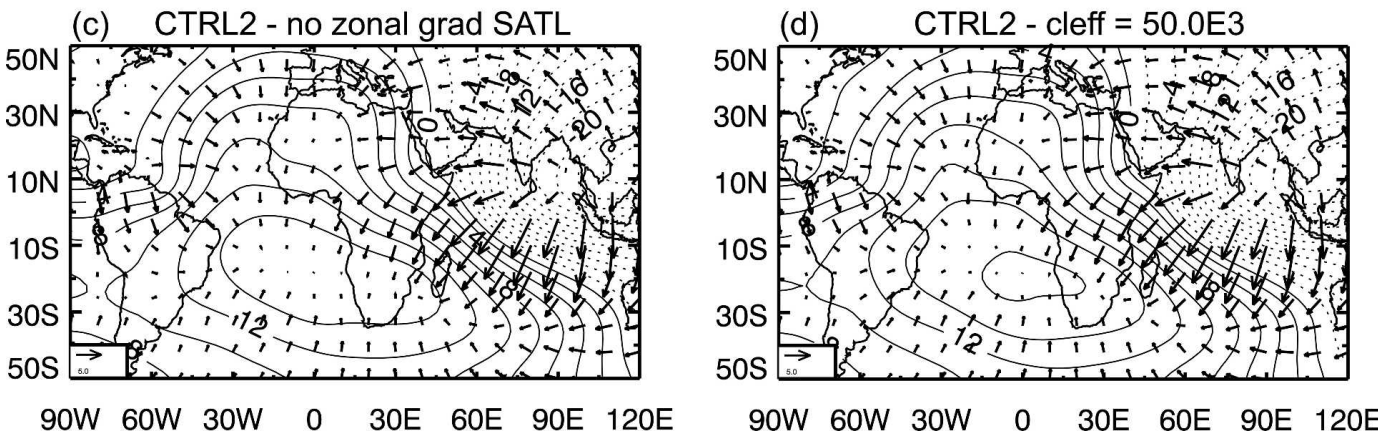

FIG. 12. Velocity potential and divergent wind in July for (a) ERA-40, (b) CTRL2, (c) an experiment in which the zonal gradient of SST is removed in the South Atlantic, and (d) an experiment with modified gravity wave drag coefficient.

parameterization. We have conducted two experiments to assess whether these parameter changes, rather than the new PBL formulation, are responsible for the improved simulation of the anticyclone in CTRL2. An experiment using the CTRL1 value for the ventilation coefficient showed no significant sensitivity and is not discussed here. The experiment concerning the gravity wave drag parameter is reported below in section $5 \mathrm{~b}$.

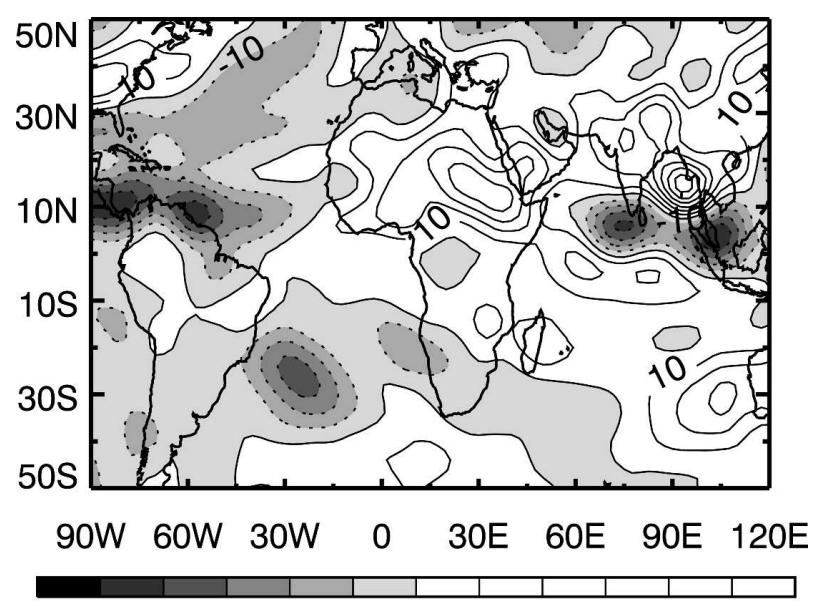

$\begin{array}{lllllllllllll}-60 & -50 & -40 & -30 & -20 & -10 & 0 & 10 & 20 & 30 & 40 & 50 & 60\end{array}$

FIG. 13. As in Fig. 12 but for SLP.

\section{a. Sensitivity to SST anomalies}

Since the South Atlantic anticyclone is well developed in CTRL2 we do not attempt to strengthen it further by increasing the zonal gradient of SST in the model's boundary conditions as was done in section $4 \mathrm{~b}$. Rather, we take the opposite approach and completely eliminate the zonal gradient in the South Atlantic between $40^{\circ}$ and $10^{\circ} \mathrm{S}$ by prescribing values that correspond to the zonal mean for each month. The results of this zonal-SST experiment are plotted in terms of upper-level divergent circulation and SLP in Figs. 12c, $13 \mathrm{c}$, respectively.

In response to the zonally uniform SSTs, the anticyclone weakens significantly on its western flank (zonal gradient at the latitude of the center reduced by about $1 \mathrm{hPa}$ per $20^{\circ}$ longitude) and shifts to the west by approximately $10^{\circ}$ (Fig. 13c), consistent with the results of Seager et al. (2003). On the eastern flank the impact is only moderate with minor changes in the zonal gradient of sea level pressure. Thus the anticyclone appears to be more sensitive to the SST changes in the west than in the east. The general features of the sea level pressure field in the SST anomaly experiment are quite similar to CTRL1. However, despite the complete lack of a zonal SST gradient, the anticyclone is still less zonal in this experiment than in CTRL1. 
(a)

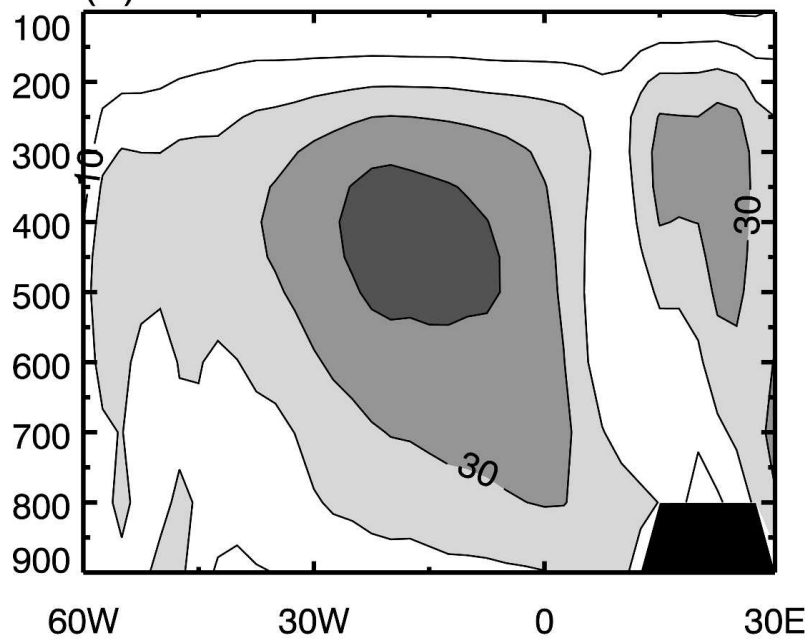

(b)

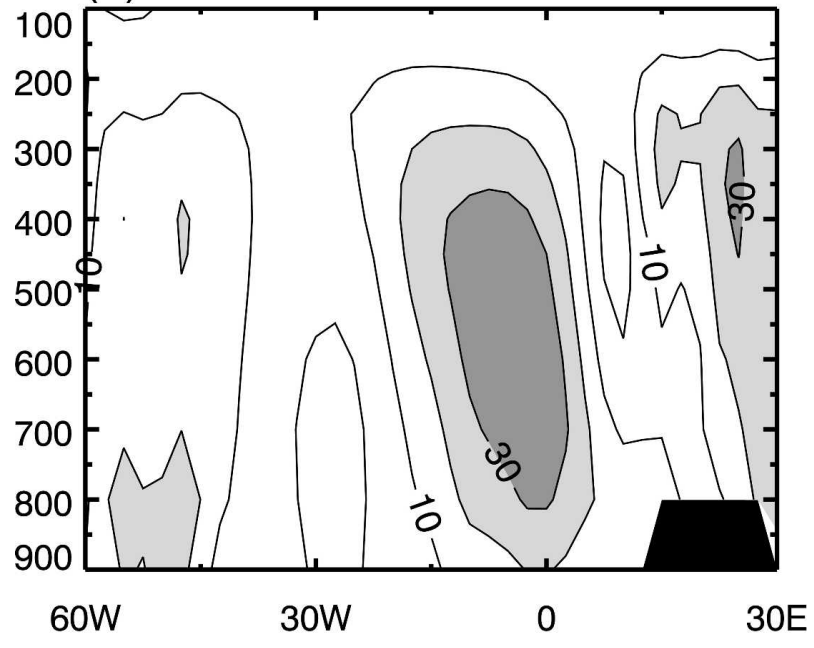

(c)

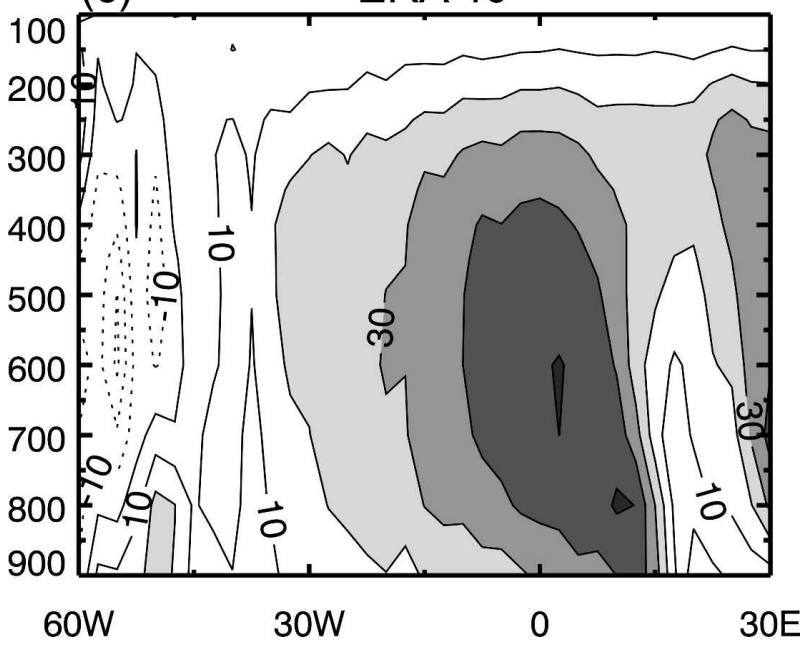

FIG. 14. Vertical $p$-velocity $\left(\mathrm{hPa}\right.$ day $\left.^{-1}\right)$ in July averaged between $30^{\circ}$ and $20^{\circ} \mathrm{S}$ in (a) CTRL1, (b) CTRL2, and (c) ERA-40. Values greater than $+20 \mathrm{hPa}$ day $^{-1}$ are shaded.
At upper levels, the divergent circulation in the zonal-SST experiment (Fig. 12c) is very similar to its counterpart in CTRL2, indicating that the regional SST anomalies have little impact on the planetary-scale circulation.

\section{b. Sensitivity to gravity wave drag}

In the last experiment we explore the sensitivity of the South Atlantic anticyclone to a parameter change in the model's gravity wave drag parameterization. This is set to the value used in CTRL1. The result is a general increase in sea level pressure over the South Atlantic combined with a slight increase in zonal pressure gradient on both the western and eastern flank (Fig. 13d). The position of the anticyclone, however, remains unchanged. This increase in sea level pressure gradient, however, does not constitute a significant intensification of the anticyclone. Consistently, the upper-level divergence shows little change (Fig. 12d). The result also suggests that the success of CTRL2 in simulating the anticyclone is not dependent on the gravity wave drag parameter.

\section{Summary and discussion}

We have analyzed control simulations and sensitivity experiments made with the UCLA AGCM with a focus on the South Atlantic anticyclone during austral winter. While the first control simulation (CTRL1) captures well the general features of the large-scale circulation compared to ERA-40, the simulated South Atlantic anticyclone is too zonally elongated and extends erroneously into the adjacent continents. Large-scale subsidence over the South Atlantic is too diffuse and lacks the well-defined maximum over the eastern Atlantic seen in the reanalysis.

These deficiencies in the CTRL1 simulation over the South Atlantic were shown to be accompanied by misrepresentations of the precipitation and surface fluxes over the African and South Asian continents, with excessive precipitation over the Ethiopian highlands in eastern central Africa and the Bay of Bengal. These result in an overly zonal monsoon zone stretching from eastern Africa to Asia, accompanied by upper-level convergence centered over the South Atlantic rather than over southern Africa as in the reanalysis. The CTRL1 simulation also underpredicts ground temperatures and overpredicts the latent heat flux over Africa, especially over the northwest between $10^{\circ}$ and $20^{\circ} \mathrm{N}$, where there is high incidence of low-level simulated cloudiness.

Our results allow for the following interpretation of 
CTRL1. The overprediction of surface latent heat flux over Africa produces intense cooling and a very stable (albeit moist) lower troposphere with little precipitation. The associated erroneous westerly winds advect moisture toward the Ethiopian highlands, where orographic uplift triggers deep convection, concentrating the latter over eastern Africa rather than over western Africa as in the reanalysis. The broad pattern of simulated upper-level divergence extending from eastern Africa to Southeast Asia is associated with a similarly broad pattern of compensating subsidence that is strongest over the central South Atlantic. This contrasts with ERA-40 where the subsidence exhibits a distinct maximum over the eastern part of the basin.

These findings motivated a series of experiments designed to explore the sensitivity of circulation over the South Atlantic and Africa to changes in the model's boundary conditions. The first set of experiments tested the impact of South American and African orography on the South Atlantic anticyclone. The results obtained confirm that the orographic effect is crucial in breaking up the wintertime high pressure belt in the subtropics. However, even the full orography used in CTRL1 is not sufficient to close off the anticyclone entirely over the ocean as in the reanalysis. Enhancing the steepness of South American orography was found to have little effect on the South Atlantic anticyclone, and a more detailed orography over southern Africa provided only a slight improvement.

Sensitivity to SST was investigated by decreasing the prescribed SSTs (up to $-3 \mathrm{~K}$ ) in the eastern South Atlantic so as to enhance the zonal SST gradient. The resulting impact was found to be rather minor, with an overall strengthening of the anticyclone, particularly on its eastern flank. The large-scale circulation, on the other hand, showed little change, suggesting that the increase of sea level pressure in the east is due to local thermodynamic effects.

Sensitivity to land conditions over the African continent was investigated by prescribing desertlike conditions over the entire continent. This led to a significant decrease in the latent heat flux over the continent, accompanied by an increase in surface temperatures of up to $8 \mathrm{~K}$ relative to the control experiment. Over northwest Africa, the drying effect was partially compensated for by an increase in moisture flux convergence from the Gulf of Guinea. Over eastern Africa, on the other hand, the excessive rainfall over the Ethiopian highlands was eliminated, leading to more realistic precipitation distribution with a maximum over western central Africa; this was accompanied by an improvement of the zonal gradient of sea level pressure in the eastern South Atlantic.
Motivated by the sensitivity of the simulated South Atlantic anticyclone to land conditions over Africa in CTRL1, we examined a new version of the model, CTRL2, in which the simulated climatology shows improvement in the features identified as important for the CTRL1 errors. In CTRL2, the South Atlantic anticyclone is strongly localized over the southeastern Atlantic. Over tropical Africa, CTRL2 exhibits more realistic values of latent heat flux over tropical Africa, together with an improved spatial distribution of precipitation over eastern Africa. Furthermore, the simulated upper-level divergent circulation in CTRL2 is much more similar to that of ERA-40, with the region of upper-level convergence realistically located over the southeast Atlantic Ocean.

A further experiment was made to determine the sensitivity of the well-developed anticyclone in CTRL2 to the zonal gradient of SST. Removing the latter did lead to a less localized anticyclone, although it remained better defined than its counterpart in CTRL1. This indicates that a reasonably well-developed anticyclone can persist in the absence of any zonal gradient in SST while, on the other hand, even a realistic distribution of SST is not sufficient to produce a realistic anticyclone. We conclude that the distribution of SST is only of secondary importance to the strength and position of the anticyclone and only becomes important when large-scale patterns of convection and subsidence allow for a realistic circulation over the South Atlantic.

The final experiment explored the sensitivity of the South Atlantic anticyclone to a parameter change in the model's gravity wave drag parameterization. Like the zonal SST gradient, the gravity wave drag parameterization seems to be only of secondary importance to the position and strength of the anticyclone.

The sensitivity to orography has not been tested again in CTRL2. Since a significant portion of the orographic impact during wintertime stems from mechanical forcing (Ringler and Cook 1999) we expect no qualitative change in the results (i.e., the mountains will still be important in splitting the wintertime high pressure belt into distinct cells).

\section{Conclusions}

The GCM experiments conducted here identify several factors controlling the strength and position of the wintertime anticyclone in the South Atlantic. The pattern of large-scale subsidence over the basin is found to play the most important role. This subsidence is in turn found to depend on tropical convection, which is largely located north of the equator during July. In particular, the convergence centers associated with the 
West African and Asian summer monsoon circulations are shown to be of consequence for the pattern of largescale subsidence over the South Atlantic. If the latter is favorable to a well-developed anticyclone, with a maximum centered over the eastern part of the basin, then secondary factors become important. These include the distribution of South Atlantic SST, orography, and ground temperatures on the adjacent continents. The first control simulation used in this study has a severe cold bias in South America and most of Africa, both of which contribute locally to the model's difficulties in closing off the anticyclone over the ocean during wintertime. In the same simulation there is excessive precipitation over eastern Africa and the Indian monsoon region that is associated with a large shift in the upperlevel patterns of convergence and divergence. These problems are, at least in part, related to the errors in the simulated surface fluxes, in particular latent heat flux. This highlights the importance of the correct treatment of the surface fluxes over the adjacent continents in coupled GCM simulations of the tropical Atlantic. The second control simulation, which features more realistic surface fluxes and a better-developed anticyclone, supports this notion. It should be noted, however, that there are more differences between the two models than just the formulation of surface fluxes. Therefore, surface fluxes might be only one of the factors responsible for the success of the second control simulation.

Another finding of note is that removing the zonal gradient of SST across the subtropical Atlantic in CTRL2 led to a clear degradation of the subtropical anticyclone, while boosting the gradient in CTRL1 was unable to overcome the deficiencies in the anticyclone in that model. In the former case our results support the hypothesis of Seager et al. (2003).

The results also illustrate that the sensitivity of an AGCM simulation to modifications in model parameters or boundary conditions can depend on how realistic the mean state is. None of the sensitivity results with CTRL1 produced a significant improvement in the simulation, which reflects the limitations of "AGCM tuning." A significant simulation improvement and weaker sensitivities were obtained after substantial model development. In our case, the results of CTRL1 and CTRL2 reinforce each other in the following way. The sensitivity to soil wetness over Africa found in CTRL1 is consistent with the improved results obtained with CTRL2: drying out the continent reduced the latent heat flux and cold bias that contributed to the errors in CTRL1, and which were alleviated in CTRL2 through changes in the PBL parameterization. Thus, while changes to the model's surface boundary condi- tions could not solve the problems, the results did point toward a resolution.

Our results highlight the important role of terrestrial processes in the climatology over the Atlantic Ocean. They also illustrate the importance of summer hemisphere monsoonal circulations for the climatological features in the winter hemisphere. Our findings lend weight to the wintertime paradigm of $\mathrm{RH}$, in which the wintertime subtropical anticyclones are considered a product of the Hadley circulation. Our results carry this further, providing evidence of the importance of the West African and Indian monsoons for the subtropical wintertime anticyclone over the South Atlantic.

A caveat to the findings discussed in the present study is the exclusion of air-sea interactions in our uncoupled AGCM simulations. This issue is important and we have taken the first steps to address it. The model used in the second control experiment has been coupled to an OGCM and the results show a quite realistic simulation of SSTs in the tropical Atlantic. We are currently analyzing this coupled model with respect to its simulation of the South Atlantic anticyclone.

Acknowledgments. This study was supported by NOAA under Grants NA03OAR4310095 and NA05OAR4310009. Model integrations were performed at the NCAR computing facilities. The ERA-40 data were provided by the European Centre for Medium-Range Weather Forecasts through their website (http://www.ecmwf.int). We thank the three anonymous reviewers for their constructive comments.

\section{REFERENCES}

Arakawa, A., and W. H. Schubert, 1974: Interaction of a cumulus ensemble with the large-scale environment. Part I. J. Atmos. Sci., 31, 674-701.

Barreiro, M., P. Chang, and R. Saravanan, 2002: Variability of the South Atlantic Convergence Zone simulated by an atmosphere general circulation model. J. Climate, 15, 745-763.

Breugem, W.-P., W. Hazeleger, and R. J. Haarsma, 2006: Multimodel study of tropical Atlantic variability and change. Geophys. Res. Lett., 33, L23706, doi:10.1029/2006GL027831.

Charney, J. G., and A. Eliassen, 1949: A numerical method for predicting the perturbations of the middle latitude westerlies. Tellus, 1, 38-54.

Cheng, M.-D., and A. Arakawa, 1997: Inclusion of rainwater budget and convective downdrafts in the Arakawa-Schubert cumulus parameterization. J. Atmos. Sci., 54, 1359-1378.

Davey, M. K., and Coauthors, 2002: STOIC: A study of coupled model climatology and variability in tropical ocean regions. Climate Dyn., 18, 403-420.

Harshvardhan, R. Davies, D. A. Randall, and T. G. Corsetti, 1987: A fast radiation parameterization for general circulation models. J. Geophys. Res., 92, 1009-1016.

,,$-- \ldots$, and D. A. Dazlich, 1989: Earth radiation budget 
and cloudiness simulations with a general circulation model. J. Atmos. Sci., 46, 1922-1942.

Huang, B., and J. Shukla, 2005: Ocean-atmosphere interactions in the tropical and subtropical Atlantic Ocean. J. Climate, 18, $1652-1672$.

Huang, H.-P., A. W. Robertson, and Y. Kushnir, 2005: Atlantic SST gradient and the influence of ENSO. Geophys. Res. Lett., 32, L20706, doi:10.1029/2005GL023944.

Kalnay, E., and Coauthors, 1996: The NCEP/NCAR 40-Year Reanalysis Project. Bull. Amer. Meteor. Soc., 77, 437-471.

Kim, Y.-J., and A. Arakawa, 1995: Improvement of orographic gravity wave parameterization using a mesoscale gravity wave model. J. Atmos. Sci., 52, 1875-1902.

Köhler, M., 1999: Explicit prediction of ice clouds in general circulation models. Ph.D. thesis, University of California, Los Angeles, $146 \mathrm{pp}$.

Konor, C. S., and A. Arakawa, 2001: Incorporation of moist processes and a PBL parameterization into the generalized vertical coordinate model. Tech. Rep. 90035, Los Angeles, CA, 63 pp. [Available online at www.atmos.ucla.edu/ csk.]

, G. Cazes, C. R. Mechoso, and A. Arakawa, 2004: Evaluation of a new PBL parameterization with emphasis on the surface fluxes. Proc. 13th Conf. on Interactions of the Sea and Atmosphere, Portland, ME, Amer. Meteor. Soc., 2.11. [Available online at ams.confex.com/ams/BLTAIRSE/techprogram/ programexpanded_248.htm.]

Large, W. G., and G. Danabasoglu, 2006: Attribution and impacts of upper-ocean biases in CCSM3. J. Climate, 19, 2325-2346.

Li, J.-L., A. Aarakawa, and C. R. Mechoso, 1999: Improved simulation of PBL moist processes with the UCLA GCM. Preprints, Seventh Conf. on Climate Variations, Long Beach, CA, Amer. Meteor. Soc., 423-426.

—, M. Köhler, J. D. Farrara, and C. R. Mechoso, 2002: The impact of stratocumulus cloud radiative properties on surface heat fluxes simulated with a general circulation model. Mon. Wea. Rev., 130, 1433-1441.

Ma, C.-C., C. R. Mechoso, A. W. Robertson, and A. Arakawa, 1996: Peruvian stratus clouds and the tropical Pacific circulation: A coupled ocean-atmosphere study. J. Climate, 9, $1635-1645$

National Oceanographic and Atmospheric Administration, 1988: Digital relief of the surface of the earth. Data Announcement 88-MGG-02, National Geophysical Data Center, Boulder, CO.

Nigam, S., I. M. Held, and S. W. Lyons, 1986: Linear simulation of the stationary eddies in a general circulation model. Part I: The no-mountain model. J. Atmos. Sci., 43, 2944-2961.

$\longrightarrow,-$, and -1988 : Linear simulation of the stationary eddies in a GCM. Part II: The "mountain" model. J. Atmos. Sci., 45, 1433-1452.

Pan, D.-M., and D. A. Randall, 1998: A cumulus parameterization with a prognostic closure. Quart. J. Roy. Meteor. Soc., 124, 949-981.

Philander, S. G. H., D. Gu, D. Halpern, G. Lambert, N.-C. Lau, T. Li, and R. C. Pacanowski, 1996: Why the ITCZ is mostly north of the equator. J. Climate, 9, 2958-2972.

Repelli, C. A., and P. Nobre, 2004: Statistical prediction of sea surface temperature over the tropical Atlantic. Int. J. Climatol., 24, 45-55.

Reynolds, R. W., and T. M. Smith, 1995: A high-resolution global sea surface temperature climatology. J. Climate, 8, 15711583.

Richter, I., and C. R. Mechoso, 2004: Orographic influences on the annual cycle of Namibian stratocumulus clouds. Geophys. Res. Lett., 31, L24108, doi:10.1029/2004GL020814.

$\longrightarrow$, and - 2006: Orographic influences on subtropical stratocumulus. J. Atmos. Sci., 63, 2585-2601.

Ringler, T., and K. H. Cook, 1999: Understanding the seasonality of orographically forced stationary waves: Interaction between mechanical and thermal forcing. J. Atmos. Sci., 56, 1154-1174.

Robertson, A. W., C. R. Mechoso, and Y.-J. Kim, 2000: The influence of Atlantic sea surface temperature anomalies on the North Atlantic Oscillation. J. Climate, 13, 122-138.

Rodwell, M. J., and B. J. Hoskins, 2001: Subtropical anticyclones and summer monsoons. J. Climate, 14, 3192-3211.

Seager, R., R. Murtugudde, N. Naik, A. Clement, N. Gordon, and J. Miller, 2003: Air-sea interaction and the seasonal cycle of the subtropical anticyclones. J. Climate, 16, 1948-1966.

Servain, J., I. Wainer, J. P. McCreary, and A. Dessier, 1999: Relationship between equatorial and meridional modes of climate variability in the tropical Atlantic. Geophys. Res. Lett., 26, 485-488.

Smagorinsky, J., 1953: The dynamical influence of large-scale heat sources and sinks on the quasi-stationary mean motions of the atmosphere. Quart. J. Roy. Meteor. Soc., 79, 342-366.

Stockdale, T. N., M. A. Balmaseda, and A. Vidard, 2006: Tropical Atlantic SST prediction with coupled ocean-atmosphere GCMs. J. Climate, 19, 6047-6061.

Suarez, M. J., A. Arakawa, and D. A. Randall, 1983: The parameterization of the planetary boundary layer in the UCLA general circulation model: Formulation and results. Mon. Wea. Rev., 111, 2224-2243.

Trzaska, S., A. W. Robertson, J. D. Farrara, and C. R. Mechoso, 2007: South Atlantic variability arising from air-sea coupling: Local mechanisms and tropical-subtropical interactions. $J$. Climate, 20, 3345-3365.

Valdes, P. J., and B. J. Hoskins, 1989: Linear stationary wave simulations of the time-mean climatological flow. J. Atmos. Sci., 46, 2509-2527.

Venegas, S. A., L. A. Mysak, and D. N. Straub, 1997: Atmosphere-ocean coupled variability in the South Atlantic. $J$. Climate, 10, 2904-2920.

Wainer, I., and S. A. Venegas, 2002: South Atlantic multidecadal variability in the climate system model. J. Climate, 15, 14081420.

Wang, H., and M. Ting, 1999: Seasonal cycle of the climatological stationary waves in the NCEP-NCAR reanalysis. J. Atmos. Sci., 56, 3892-3919.

Xie, S.-P., and J. A. Carton, 2004: Tropical Atlantic variability: Patterns, mechanisms, and impacts. Earth Climate: The Ocean-Atmosphere Interaction, Geophys. Monogr., Vol. 147, Amer. Geophys. Union, 121-142. 